\title{
NOTAS SOBRE LAS FUNCIONES DEL ALBACAR EN LAS FORTIFICACIONES DEL NORTE DE ÁFRICA
}

Por

CARLOS GOZALBES CRAVIOTO

En los últimos años, hemos comprobado la existencia de una polémica sobre las funciones de una estructura aneja a la fortificaciones medievales. Nuestro estudio de las fortificaciones del norte de África, creemos que aporta nuevos datos de interés y es por ello, por lo que vamos a exponerlos en este pequeño trabajo.

Algunos investigadores, al realizar trabajos de arqueología en la zona valenciana, han demostrado la existencia de amplios recintos alrededor de las torres defensivas y castillos, construidos muy sencillamente, con tan solo una tapia baja. La misma estructura, hemos encontrado en otras fortificaciones medievales de la provincia de Málaga, tales como por ejemplo la torres fortificadas de Torre Árboles y Cantarrayán y los castillos de Santi Petri y Xebar. Este tipo de recinto, en las fortificaciones de ciudades o de grandes castillos, está documentado con el nombre de "albacar", diferenciándose claramente de los recintos de las barbacanas. Sin duda, la falta de documentación que asigne el nombre de "albacar» a estos recintos en las pequeñas fortalezas, es debida precisamente a la poca importancia de estas fortificaciones, pero pensamos que su denominación es correcta.

Al igual que otros autores (1), no estamos de acuerdo con las funciones otorgadas a estos recintos por parte de los arqueólogos e historiadores franceses, que en una magnífica labor, han localizado, excavado y estudiado una gran cantidad de torres, alquerías y castillos con sus correspondientes «albacares» en la zona valenciana (2). De su existencia, sacan unas conclusiones

(1) EPALZA, MÍKEL. "Funciones ganaderas de los albacares en las fortalezas musulmanas». Sharq Al-Andalus Alicante 1984. Pág. 47-54. BEVÍA, MARIUS. "L'albacar musulmà del castell d'Alacant". Sharq AlAndalus. 1. Alicante 1984. Pág. 131-140.

(2) BAZZANA, A. y GUICHARD, P. «Les tours de défense de la Huerta de Valencia au XIII siècle». Melanges Casa Velázquez. París 1978. Pág. 73-105. GUICHARD, P. "Le problème de l’existence de structures 
que creemos erróneas. Piensan que el «albacar», es una construcción defensiva, construida por el señor del lugar, para que, en caso de ataque, se encerrase en el recinto toda la población de los alrededores, con sus bienes. Ello, a su vez, es base para suponer un proceso de pseudofeudalismo.

Pensamos que esta idea, es rebatible desde todos los puntos de vista.

Arqueológicamente la endeblez de estos muros del albacar, su baja estatura y el hecho de que, en algunos casos, este recinto estuviera abierto en amplias zonas (seguramente cerrado por ramas o vallas de madera), se contradice con la de una estructura defendible.

Etimológicamente, la procedencia del nombre de albacar, es decir «las vacas", e incluso sus funciones ganaderas, han sido estudiadas por Míkel de Epalza en las páginas de esta misma revista (3). Por ello, solo vamos a indicar los datos que nos aportan al respecto las fortificaciones del norte de África (4).

CEUTA. En Ceuta, el Albacar, se sitúa en la zona N. O. de la ciudad, cerrado al este por las murallas y por el oeste, por una de las corachas (5). En época medieval, se situaban en sus cecanías, el barrio Al-Kassabun (Los Carniceros) y la fonda Al-Ganim (Las ovejas). En la década 1540-1550, cambió totalmente de estructura, al modificar los portugueses sus fortificaciones, adaptándolas al uso de la artillería. Se siguió designando a la zona como «Albacar», estando documentada hasta principios del siglo XIX (6).

ARCILA. El Albacar se situaba dando al mar y la documentación que lo cita profusamente (7), no cita más que la "porta do albacar», sin relacionarlo directamente con el ganado. Esto es, porque pervivió su nombre, pero no sus funciones. Al ser en principio un espacio demasiado grande, se redujo, que-

du type "feodal" dans la société d'Al Andalus (l'exemple de la région valencienne). Structures féodales et féodalisme dans I'Occident Méditérraneén (X-XIll siècles)m. Roma 1980. Pág. 699-725. BAZZANA. A. "Elements d'archéologie musulmane dans Al-Andalus. Caractères spécifiques de l'architecture mititaire arabe dans la région valencienne". Al-Qanțara I. 1980. Pág. 339-364. IDEM. "Albacar: Ia fonction réfuge dans le château hispano-musulmane de la région valenciennes. Châteaux et peuplements en Europe Occidentale du X au XVIII siécle. Auch. 1980. Pág. 192-197. IDEM. "Prémiers élements d'une carte archéologique du Sharq Al-Andalus". Archéologie Médievale X. 1980. Pág. 323-325. IDEM. "La defense des communautés rurales dans l'Espagne musulmanem. Perpectives aériennes. Les paysages et leur histoire. París 1983. Pág. 105-122. También el libro colectivo: Habitats fortifiés et organisation de l'espace en Méditerranée Occidentale. Lyon 1983.

(3) EPALZA, M. O. C. y TERES, E. "Al-Aqaba. Notas de toponimia árabe». Al Andalus XLIll. 1978. Páginas $370-371$.

(4) Resumimos los datos de nuestro trabajo: "El albacar en las fortificaciones hispano-portuguesas del norte de África». I er Congreso Hispano Africano de las Culturas Mediterráneas. Melilla 1984. Actas en prensa.

(5) GOZALBES CRAVIOTO, CARLOS. "Las corachas hispano-musulmanas de Ceutan. Al-Qanțara. 1. 1980 Pág. 365-384

(6) GOZALBES CRAVIOTO, CARLOS. «El aibacar en las fortificaciones de Ceuta». Jábega 29. Málaga 1980. Pág. 61-65 y "Las fortificaciones hispano-portuguesas del frente de tierra de Ceuta. 1. (1550-1640 $\mathrm{m}$. Transfretana. II. Ceuta 1982. Pág. 19-50.

(7) RODRIGUES, BERNARDO. "Anais de Arzila. Crónica inédita do seculo XVin. Ed. David Lopes. Lisboa 1915. 
dando la puerta del albacar fuera del recinto. Esta parte del antiguo albacar, ya no se denomina como tal, sino como "cural das vacas» (8).

ALCAZARSEGUER. No se cita en la documentación el nombre de albacar, sino un corral de ganado, situado en las afueras de la ciudad y de las fortificaciones. Ello era debido a que no existía espacio suficiente entre la muralla, la barbacana y el foso, para construir un recinto para ganado (9). Por esto pensamos que a los corrales de ganado se les denominaba "albacar", sólo cuando estaban cerrados por las murallas o por las fortificaciones anejas.

TÁNGER. Constituye un caso insólito, pues el «albacar», se forma ya tardíamente y en el interior de las murallas de la ciudad. Al conquistar los portugueses la ciudad, se ven obligados a abandonar una gran parte de ella. Se plantean incluso reducir sus muros, pero finalmente, se deja intacto el recinto medieval (10). Con ello, quedó una gran zona desértica, cuyas construcciones tuvieron que ser demolidas para evitar que en ella se escondieran los musulmanes que lograban penetrar furtivamente en la fortaleza, debido a que por su extraordinaria longitud, era muy difícil de controlar en toda su extensión, sobre todo por la noche. Este extenso campo, es observable en el mapa de Tánger de Georgius Braun y constituyó el «albacar» (11).

Del estudio de estas fortificaciones, sacamos las siguientes conclusiones:

- El término de "albacar», se aplica a un recinto para guardar ganado.

- En todos los casos en los que está documentado, el "albacar», está limitado en uno de sus laterales, por el recinto de la ciudad o de sus fortificaciones complementarias (barbacana, coracha, albarrana, etc.) En el único caso, en el que el ganado se encerraba en un lugar no documentado como albacar, es en Alcazarseguer, en el que el corral del ganado estaba al exterior de las fortificaciones, sin relación directa con ellas.

- En el siglo XV, en las crónicas portuguesas, se le da la denominación de albacar a un espacio que antes era urbano y que estaba cerrado por las propias murallas de la ciudad (Tánger). Esto demuestra que el término siguió utilizándose en dicho siglo y también, en este caso, la función del "albacar» era la de la guarda del ganado.

- Debemos descartar por completo, que en estas ciudades, ya portuguesas en el siglo XV, el albacar fuera un recinto eminentemente defensivo,

(8) Si observamos un dibujo de Arcila en 1700, podemos observar que lo que seguramente se hizo, fue hacer más pequeño el albacar, con lo que su antigua puerta, quedó aislada, aunque manteniendo su nombre.

(9) Sobre las fortificaciones de Alcazarseguer, véase nuestro trabajo: "Las corachas portuguesas de Alkazarseguer". Cuadernos de la Biblioteca Española de Tetuán. N. ${ }^{\circ} 15$. Tetuán 1977. Pág. 49-61.

(10) MENESES, FERNANDO. "Historia de Tangere". Lisboa 1732. Pág. 39.

(11) ALVARES, JOAO. "Chronica do Infante Santo D. Fernando". Coimbra 1911. Pág. 30 
destinado a proteger a los habitantes de los alrededores, puesto que precisamente, lo que se quería, era proteger a la ciudad de sus inmediatos vecinos. Por delante de los "albacares" de estas fortificaciones, existian una serie de tapiales bajos, llamados por los portugueses "tranqueiras", destinados a proteger las salidas en busca de leña y a dificultar la retirada y el ataque rápido a los musulmanes que atacasen las plazas (12), pero eso, ya es otro tema.

En base a nuestros estudios sobre las fortificaciones del norte de Africa, definimos el albacar como un recinto con tapiales bajos, destinado a guardar ganado y protegido en uno de sus flancos por las fortificaciones de la ciudad.

Sabemos que estas fortificaciones, guardan unas características que podrian diferenciarse con las del resto del Al-Andalus, también sabemos que llo mismo que en el resto de las zonas geográficasl, las fuentes documentales sobre los albacares, en su mayoría son tardías, pero todo demuestra que el albacar era un recinto ganadero. El que fuera utilizado circunstancialmente como defensivo, no implica que esa fuera su originaria y principal función.

(12) Sobre el sistema defensivo portugués de "tranqueiras, véase nuestros trabajos: "Los fachos de Ceuta, almenaras de la costa malagueña». Jábega n. 27. Málaga 1979. Pág. 21-27 y aLas fortificaciones hispano portuguesas del frente de tierra de Ceutam. O. c.

TANGER a mediados del siglo XVI. De la obra de Georgius Braun.
A: Albacar
B: Coracha nueva
C: Coracha vieja
D: Puerta de la Traición

Arcila en 1700

A: Albacar (porta)

B: Corral de las vacas (localización del autor) 